\title{
Relationship between feeding practices and morbidity pattern of children under two years of age in a community setting at Mymensingh
}

\author{
${ }^{*}$ Khan $\mathrm{MI}^{1}$, Hoque $\mathrm{MA}^{2}$, Begum $\mathrm{B}^{3}$, Hasan $\mathrm{MM}^{4}$, Awual SMA ${ }^{5}$
}

\section{Abstract}

This descriptive cross-sectional study was performed in the department of Pediatrics, Mymensingh Medical College Hospital to assess the feeding practices and their relationship with the morbidity pattern of children under two years of age. For this study four hundred (400) children from eight different Upazilla Health Complexes (UHC) of Mymensingh district were enrolled and UHCs were selected randomly. Mothers with their children under two years of age who gave voluntary, informed, written consent were included and very sick children, motherless children, handicapped children were excluded from the study. Immediately after registration, detailed history was taken from child's mother using a preset questionnaire and clinical examination (anthropometry and bipedal edema) was done. Among them, 214 children $(53.5 \%)$ were male and 186 children (47.5\%) were female and $M$ : $F=1.2: 1$. Regarding morbidity pattern, $17.3 \%$ had acute respiratory tract infection (ARI), $12.7 \%$ had acute watery diarrhea (AWD), 2.2\% had dysentery, and 9.5\% children had more than one disease. In exclusive breast feeding (EBF), acute respiratory tract infection was $10.24 \%$ where as in partial breast feeding it was $23.24 \%$ and acute watery diarrhea in exclusive breast-fed baby was $6.6 \%$ but in partial breast-fed baby it was $17.29 \%$. Morbidity were more in children who started complementary feeding with luta, barley, suji and cow's milk with suji than with khichuri and mixed family diet.

Keywords: Feeding practice, Morbidity pattern, Malnutrition.

\section{Introduction}

First two years of life is critical in terms of one's physical, mental and social development. Optimal infant and young child feeding practices gives a child's best possible start of life. It is not only ensures adequate nutrition but also boosts immunity thus helps in preventing various morbidities. $^{1,2}$ A malnourished child is vulnerable to various morbidities which at times may have fatal outcome. High rates of infection have detrimental effect on a child's growth and development. It had been seen that an undernourished child may have cognitive impairment, growth retardation, and compromised educational achievement and less economically productive in later course of life. Worldwide, more than 170 million children do not have the opportunity to reach their full potential because of poor nutrition in the earliest months of their life.

World Health Organization (WHO) and UNICEF have developed the global strategy for Infant and Young Child Feeding (IYCF) with recommendations of continued breastfeeding till 2 years with 6 months of exclusive breastfeeding, or feeding with appropriate iron rich foods if not breastfed, feeding solid or semisolid food for a minimum number of times per day according to age and breastfeeding status and including foods from a minimum number of food groups per day according to breastfeeding status. ${ }^{6}$ It has been suggested that $20 \%$ of under -5 deaths could be prevented ${ }^{7}$ if all IYCF indicators are

1. Dr. Mohammad Monirul Islam Khan; Assistant Professor (Pediatrics), Shaheed Syed Nazrul Islam Medical College, Kishoreganj.

2. Professor Dr. Mohammad Azizul Hoque; Ex- Head, Department of Pediatrics, Mymensingh Medical College, Mymensingh.

3. Dr. Bilkis Begum; Assistant Professor (Pediatrics), Mymensingh Medical College, Mymensingh.

4. Dr. Mohammad Mahmudul Hasan; Assistant Professor (Pediatrics), Mymensingh Medical College, Mymensingh.

5. Dr. S. M. Abdul Awual; Assistant Professor (ENT), Sir Salimullah Medical College, Dhaka.

Address of correspondence: Email:mikhan29@gmail.com Mobile: 01711361349 
achieved and $\sim 22 \%$ of neonatal deaths could be averted with optimal breastfeeding. ${ }^{8}$

The establishment of feeding practices that are comfortable and satisfying for both the parents and the infant is crucial not only for the emotional wellbeing of both but also for ensuring adequate nutrient intakes for the infant. ${ }^{9}$ Appropriate feeding practices are of fundamental importance for the survival, growth, development, health and nutrition of infants and children everywhere. ${ }^{10}$ There are many factors affecting infant feeding patterns. These can be broadly categorized as social factors (level of education, social and cultural statuses and economic condition of parents), nutritional and health statuses of mother and infants, bioavailability of nutrients and composition of nutrients in food and government policies. $^{11}$

More appropriate feeding practices are associated with greater gain in weight and length during infancy. ${ }^{12}$ There are three determinants of good health, nutrition and child survival - these are food security, caring practice and disease control. Breastfeeding is an excellent example of all these three things in one. ${ }^{13}$ Optimal infant and young child feeding (IYCF) is very much important as deaths associated with inappropriate feeding practices mostly occur during the first year of life. If it continues through second birth day, children could suffer from irreversible physical and cognitive damage. ${ }^{14}$

The Ghana study shows that breastfeeding starting within one hour of birth could reduce $22 \%$ of all neonatal mortality; this effect is independent of exclusive breastfeeding. ${ }^{15}$

Universalization of exclusive breastfeeding was shown to cut down $13-15 \%$ of all child deaths. ${ }^{16}$ The duration of exclusive breastfeeding in Bangladesh is low. Women with higher education, high economic level, lower birth interval and delivery assisted by health personnel had lower duration of breast feeding. ${ }^{17}$ Many mothers neither exclusively breastfed for the first six months of the baby's life nor continue breastfeeding for the recommended two years or more and instead replace breast-milk with commercial or other substitutes. ${ }^{18}$ During the critical period of infancy, breastfeeding and weaning practices play an important role in determining the growth of an infant. ${ }^{19}$ Malnutrition and mortality among infant and children in developing countries are major health problems, mainly associated with unhygienic feeding practices. Diarrhea and respiratory tract infections in partially breastfed and totally bottle-fed children is higher than exclusively breastfed children. ${ }^{20}$ Breastfeeding provides significant protection against infection in newborns and infants. It is estimated that an increase in breast feeding worldwide by $40 \%$ would reduce death from respiratory infections by $50 \%$ in children less than 18 months of age. Recent investigations show that respiratory tract infections and asthma are reduced in breastfed infants. ${ }^{21}$ Breast fed babies show a better gain in weight during the first seven months of life than bottle fed babies which also had a significantly higher incidence of diarrhea and hospital experience from birth through twelve months of age. ${ }^{22}$

Most of the studies conducted in Bangladesh have focused only on breastfeeding aspects but studies on dietary diversity and diet frequency aspects are scarce which are important for IYCF practices. Studies exploring relationship between morbidity and feeding practices are very few in number. With this background, this study was undertaken to assess the feeding practices and morbidity profile of children aged less than 24 months of age in a community setting at Mymensingh, Bangladesh. The study will enable policymakers to design suitable interventions to improve the health status of children.

\section{Methods}

This descriptive cross-sectional study was performed in the department of Pediatrics, Mymensingh Medical College Hospital, Mymensingh during the period of November 2009 to May 2010. As the actual prevalence of feeding practices in this age group was unknown, it was taken as $50 \%$ and the total 
sample size calculated was 384 . But for the simplicity of calculation 400 consecutive children under 2 years of age with their mothers were included and very sick children, motherless children, handicapped children were excluded. The samples were collected from the pediatric outpatient department (OPD), oral rehydration therapy (ORT) corner and expanded program on immunization (EPI) corner of eight upazilla health complexes (50 consecutive samples from each upazilla health complex) of Mymensingh district who fulfilled the inclusion and exclusion criteria and gave informed, voluntary, written consent to enroll in the study. The interview was taken by the investigator himself using a preset questionnaire. Immediately after registration detailed history was taken from child's mother, this includes age of the child in full months, maternal age, education, socioeconomic status of the family, birth history of the child including term or preterm, place of birth, mode of delivery. Then detailed feeding history were collected from the mother using 24 hours recall method including first feeding, colostrum, type of pre-lacteal food if given, breast feeding status whether the child was exclusively, predominantly or partially breast fed and average duration of breast feeding. Then complementary feeding history including timing and type of complementary food were taken. Finally, any history of illness e.g. acute respiratory tract infection, acute watery diarrhea, dysentery etc. in the past were taken. Then weights of the children were measured by conventional beam scale (Camry, China) which is accurate to $50 \mathrm{gm}$ and were calibrated before every measurement. Weighing were carried out by keeping the baby nude and before feeding. Then lengths of the child were measured by using infantometer to the nearest $1 \mathrm{~mm}$. Then bilateral pedal edema was examined by applying pressure over the dorsum of the foot for about 10 seconds. Finally, weight for age, height for age and weight for height were calculated in both percentile and $Z$ score. After data collection, data was sorted, scrutinized by the researcher himself by the selection criteria and then data were analyzed by calculator and personal computer by software SPSS version 15 (Statistical package for social science). Comparison of parameters were done by Chi-square test. Level of significance was considered as $p$ value less than 0.05 .

\section{Results}

Maximum numbers of children were in between the age of 6 to 14 months of age group, i.e. 293 in number $(73.1 \%)$. Infant less than 6 months of age were 21 (5.3\%) and more than 18 months of age were 55 (13.8\%). Out of 400 children, 214 children $(53.5 \%)$ were male and 186 children $(46.5 \%)$ were female and Male: Female $=$ 1.2:1

Table 1. Distribution of children according to types of morbidity

\begin{tabular}{|l|c|c|}
\hline Moribidity pattern & Frequency & Percentage \\
\hline Respiratory tract infection & 69 & 17.3 \\
\hline Acute watery diarrhea & 51 & 12.7 \\
\hline Dysentery & 9 & 2.2 \\
\hline Others & 13 & 3.3 \\
\hline None & 258 & 64.5 \\
\hline Total & 400 & 100.0 \\
\hline
\end{tabular}

In this study it was shown that $17.3 \%$ (69 children) had acute respiratory tract infection (RTI), $12.7 \%$ had acute watery diarrhea (AWD), 2.2\% had dysentery and $3.3 \%$ had other diseases like skin and soft tissue infection, oral thrush etc. 9.75\% (39 children) had more than one disease during the period (up to 24 months of age).

Table 2: Distribution of children by breast feeding in relation to morbidity pattern

\begin{tabular}{|c|c|c|c|c|c|c|}
\hline \multirow{2}{*}{\begin{tabular}{|l|} 
Breast \\
feeding \\
status
\end{tabular}} & \multicolumn{6}{|c|}{ Morbidity pattern } \\
\hline & RTI (\%) & ) AWD (\%) & Dysentery (\%) & Others (\%) & None (\%) & Total $(\%)$ \\
\hline Exclusive & e17(4.25) & $11(2.75)$ & $0(0)$ & $0(0)$ & $138(34.5)$ & $166(41.5)$ \\
\hline Partial & $43(10.75)$ & ) $32(8)$ & $5(1.25)$ & $6(1.5)$ & $99(24.75)$ & $185(46.25)$ \\
\hline Predominant & it $8(2)$ & $6(1.5)$ & $3(0.75)$ & $4(1)$ & $12(3)$ & $33(8.25)$ \\
\hline Not at all & $\| 1(0.25)$ & $2(0.5)$ & $1(0.25)$ & $3(0.75)$ & $9(2.25)$ & $16(4)$ \\
\hline Total & $69(17.25)$ & $51(12.75)$ & $9(2.25)$ & $13(3.25)$ & $258(64.5)$ & $400(100)$ \\
\hline
\end{tabular}

Table 2 showed that respiratory tract infection $(62.32 \%)$, acute watery diarrhea $(62.74 \%)$, dysentery (55.56\%) and other diseases $(46.15 \%)$ were common in partially 
breast-fed group than exclusive or predominant breastfed group and it was highly significant $(p<0.001)$.

Table 3: Distribution of children by timing of start of complementary feeding in relation to morbidity pattern

\begin{tabular}{|lcccccc|}
\hline $\begin{array}{l}\text { Timing of } \\
\text { start of } \\
\text { complementary }\end{array}$ & \multicolumn{5}{c|}{ Morbidity pattern } \\
\cline { 2 - 7 } feeding & AWD (\%) & Dysentery (\%) & Others (\%) & None (\%) & Total (\%) \\
\hline Timely, at $6 \mathrm{~m}$ & $21(5.25)$ & $12(3)$ & $0(0)$ & $0(0)$ & $110(2.5)$ & $143(35.75)$ \\
Early, $66 \mathrm{~m}$ & $27(6.75)$ & $25(6.25)$ & $5(1.25)$ & $4(1)$ & $116(29)$ & $177(44.25)$ \\
Delayed, $>7 \mathrm{~m}$ & $16(4)$ & $12(3)$ & $4(1)$ & $6(1.5)$ & $21(5.25)$ & $59(14.75)$ \\
Not at all & $5(1.25)$ & $2(0.5)$ & $0(0)$ & $3(0.75)$ & $11(2.75)$ & $21(5.25)$ \\
Total & $69(17.25)$ & $51(12.75)$ & $9(2.25)$ & $13(3.25)$ & $258(64.5)$ & $400(100)$ \\
\hline
\end{tabular}

In table 3, it was shown that those children who took complementary feeding early $(<6$ months of age) suffered more than timely starting group and it was highly significant $(p<0.001)$.

Table 4: Distribution of children by weight for height in relation to morbidity pattern

\begin{tabular}{|lcccccc|}
\hline Weight for & \multicolumn{5}{c|}{ Morbidity pattern } \\
\cline { 2 - 6 } height & $\mathrm{RTI}(\%)$ & AWD (\%) & Dysentery $(\%)$ & Others $(\%)$ & None $(\%)$ & Total $(\%)$ \\
\hline$<-3 \mathrm{SD}$ & $3(0.75)$ & $5(1.25)$ & $2(0.5)$ & $0(0)$ & $0(0)$ & $10(2.5)$ \\
$-2 \mathrm{SD}$ & $24(6)$ & $15(3.75)$ & $4(1)$ & $2(0.5)$ & $0(0)$ & $45(11.25)$ \\
-2 or more SD & $42(10.5)$ & $31(7.75)$ & $3(0.75)$ & $11(2.75)$ & $258(64.5)$ & $345(86.25)$ \\
Total & $69(17.25)$ & $51(12.75)$ & $9(2.25)$ & $13(3.25)$ & $258(64.5)$ & $400(100)$ \\
\hline
\end{tabular}

Table 4 showed that children those who were underweight, wasted and stunted suffered more from infection like respiratory tract infection, acute watery diarrhea, dysentery etc. It was statistically significant $(p<0.001)$.

Table 5: Distribution of children by types of complementary feeding in relation to morbidity pattern

\begin{tabular}{|lcccccc|}
\hline \multirow{5}{*}{ Complementary } & \multicolumn{5}{c|}{ Morbidity pattern } \\
\cline { 2 - 7 } & feeding type RTI (\%) & AWD (\%) & Dysentery (\%) & Others (\%) & None (\%) & Total (\%) \\
\hline Khichuri & $5(1.25)$ & $5(1.25)$ & $2(0.5)$ & $2(0.5)$ & $60(15)$ & $74(18.5)$ \\
Cow's milk & $11(2.75)$ & $9(2.25)$ & $2(0.5)$ & $3(0.75)$ & $73(18.25)$ & $98(24.5)$ \\
with suji & & & & & \\
Luta, Barley, & $36(9)$ & $25(6.25)$ & $4(10$ & $6(1.5)$ & $76(19)$ & $147(36.75)$ \\
Suji & & & & & \\
Rice & $4(1)$ & $2(0.5)$ & $0(0)$ & $0(0)$ & $23(5.75)$ & $29(7.25)$ \\
Cereal & $3(0.75)$ & $4(1)$ & $0(0)$ & $0(0)$ & $4(1)$ & $11(2.75)$ \\
Banana & $2(0.5)$ & $1(0.25)$ & $0(0)$ & $0(0)$ & $3(0.75)$ & $6(1.5)$ \\
Mixed & $3(0.75)$ & $4(1)$ & $1(0.24)$ & $1(0.25)$ & $5(1.25)$ & $14(3.5)$ \\
Not yet started & $5(1.25)$ & $1(0.25)$ & $0(0)$ & $1(0.25)$ & $14(3.5)$ & $21(5.25)$ \\
Total & $69(17.25)$ & $51(12.75)$ & $9(2.25)$ & $13(3.25)$ & $258(64.5)$ & $400(100)$ \\
\hline
\end{tabular}

Table 5 showed that morbidity was more in children who started complementary feeding with luta, barley, suji and cow's milk with suji than who started with khichuri or mixed food and it was statistically significant $(p<0.01)$.

\section{Discussion:}

The improper infant feeding practices can be extremely detrimental to the health and wellbeing of the infant with high morbidity and mortality. ${ }^{23}$ Mortality rate for term babies in early infancy can be reduced by simultaneous promotion of breast feeding and prevention of low birth weight. ${ }^{24}$ Over one third (3.5 million) of about 10 million children die annually due to under nutrition. ${ }^{25}$ Over two-thirds of these deaths, which are often associated with inappropriate feeding practices, occur during the first year of life. ${ }^{26}$

Recent research shows that $22 \%$ of new born deaths could be prevented if newborns initiate breastfeeding within one hour of birth and $13 \%$ under five mortality rate will be reduced by exclusive breastfeeding up to six months and continued breastfeeding with proper complementary feeding up to two years will further reduce $6 \%{ }^{27}$

The international code of breast milk substitute reported that improper feeding increases infant morbidity, diseases and infections. ${ }^{28}$ Diarrhea and respiratory tract infection in partial breastfed and total bottlefed children found much higher than exclusively breastfed children. ${ }^{20}$ The mean monthly episode of diarrhea was 2.0 and 2.4 for those who were partially breast fed for 12 months and 12-18 months respectively, while respiratory tract infection was 1.8 and 3.0 for the same period of partial breast feeding.

A study performed in Mexico in 1990 concluded that non breast-fed infants (up to six months of age) had 2.3 times greater risk of developing diarrhea than breast-fed infants. ${ }^{29}$ Breast feeding confers protection against shigellosis till three years of age. ${ }^{30}$ The estimated benefit from breast feeding is a decrease in diarrheal morbidity by $8-20 \%$ and a decrease in diarrheal mortality rate by $24-27 \%$ in the first six months of life. Prolonged breastfeeding 
beyond one year in a cohort of 1087 Bangladeshi children was associated with a 6 -fold increase in survival compared to nonbreastfed children. ${ }^{32}$

A prospective study in India showed that breastfed children hospitalized with diarrhea were three times more protected against death compared to non-breastfed children. ${ }^{33}$

The recent Lancet series on maternal and child under nutrition has concluded that the relative risk for all cause of mortality is 1.48 and 2.85 for predominant breastfeeding (breastfeeding plus water) and partial breastfeeding as compared to exclusive breastfeeding; the relative risk of diarrhea mortality is 2.28 and 4.62 and pneumonia mortality is 1.75 and 2.49 for predominant and partial breastfeeding as compared to exclusive breastfeeding and the relative risk for prevalence of diarrhea is 1.26 and 3.04 and for pneumonia is 1.79 and 2.49 for predominant and partial breastfeeding as compared to exclusive breastfeeding. ${ }^{25}$

Morbidity pattern of children in this study showed that among 400 children $17.3 \%$ had acute respiratory tract infection, $12.7 \%$ had acute watery diarrhea, $2.2 \%$ had dysentery, and $9.5 \%$ children had more than one disease within the two years of age. The BDHS preliminary report (2007) showed that in $<2$ years children incidence of ARI was $17.03 \%$ and AWD was $10.9 \% .^{27}$ This result is very much close to this study. In exclusive breast-feeding ARI was $10.24 \%$ where as in partial breast feeding it was $23.24 \%$ and AWD in exclusive breast-fed baby $6.6 \%$ but in partial breast-fed baby it was $17.29 \%$. Chitkara AJ showed the incidence of morbidity in these diseases were much more (8.16 episodes/child/year) in non-exclusive breast-fed children than in exclusive breastfed children (4.06 episodes/child/year). ${ }^{34}$

A study done by NehaKapoor and RajiniThapa found that mothers who were not following the feeding practices accurately which affects the health of the children \& Diarrhea and ARI's were the most frequently occurring morbidities among the children under 2 years of age. ${ }^{35}$
Delaying the introduction of formula milk protects against morbidity associated with respiratory infection, illness, and associated hospitalizations in the first year of life. ${ }^{21}$ In this cross-sectional study information about the feeding practices of infants and their morbidity pattern of different age group were collected by taking mothers' interview. The main problem was the recall bias about the past feeding practices of children and past illness by the mothers, which may be poor in some instances and give rise to erroneous report. Incorrect statement about the child's age by the uneducated mother was another potential problem. Despite these demerits the investigator tried his best to collect the accurate information during interviewing the mother by giving enough time to recall.

\section{Conclusion}

Feeding practices of children was not at all satisfactory. There was high burden of morbidity. Unsatisfactory feeding practices adds on to the burden. At every given opportunity health care providers should enquire to mothers of young child regarding their child feeding practices to identify and intervene at the earliest. Mother of the child should be counselled in easily comprehensible local language regarding benefits of optimum feeding practices in ensuring their child health.

\section{References}

1. WHO/ UNICEF. Global Strategy for Infant and Young Child Feeding 2003. [Last accessed on 2017 Jun 24]

2. Guidelines for Enhancing Optimal Infant and Young Child Feeding Practices. Ministry of Health and Family Welfare, Government of India.; 2013. [Last accessed on 2017 Jun 24]

3. Oddy WH, Kendall GE, Blair E, De Klerk NH,

Stanley FJ, Landau LI et al. Breast feeding and cognitive development in childhood: a prospective birth cohort study. PaediatrPerinatEpidemiol 2003:17[1]:81-90.

4. Grantham-McGregor $S$, Cheung YB, Cueto $S$, Glewwe $P$, Richter L, Strupp B, et al.

Developmental potential in the first 5 years for children in developing countries. Lancet 2007;369[9555]:60-70.

5. Victora CG, Adair L, Fall C, Hallal PC, Martorell $R$, Richter $L$, et al. Maternal and child undernutrition: consequences for adult 
health and human capital. Lancet 2008;371[9609]:340-57

6. World Health Organization [WHO]. Young Child Feeding Global Strategy for Infant and.; Available from: http:// apps. who.int/ iris/ bitstream/ 10665/ 42590/ 1/92415 62218.pdf [Last accessed on 2017 Jun 25]

7. Jones G, Steketee RW, Black RE, Bhutta ZA, Morris SS. How many child deaths can we prevent this year? Lancet 2003;362[9377]:65-71.

8. Edmond KM, Kirkwood BR, Amenga-Etego S, Owusu-Agyei S, Hurt LS. Effect of early infant feeding practices on infection-specific neonatal mortality: an investigation of the causal links with observational data from rural Ghana. Am J Clin Nutr 2007;86[4]:1126-31.

9. Kliegman RM, Behrman RE, Jensen $H B$, Stanton BF.The feeding of infants and young children. In: Nelson Text Book of Pediatrics. 18th ed. Saunders,2007: 214-224.

10. Institute of Child and Mother Health. Training on Complementary Feeding under HNPSP. ICMH, Dhaka. 2006: 3-6.

11. Hayrli $A$, Kisa $F$. Infant feeding patterns a mini review on evaluation of infant feeding in several aspects: Pakistan Journal of social sciences. 2005. 3(4): 661-664.

12. Shaha KK, Frongillo EA, Alam DS, Arifeen SE, Person LA, Rasmssen KM. Appropriate infant feeding practices result in better growth in infants and young children in rural Bangladesh. Am J Clin Nutr. 2008; 87(6), 1852-1859.

13. Talukder MQ- K. Breastfeeding: Healthy Mothers and Healthy Babies. World Breastfeeding Week. Bangladesh Breast Feeding Foundation. 2002: 1-3.

14. Black RE, Allen LH, Bhutta ZA, Caulfield LE, de Onis M, Ezzati $M$, et al. Maternal and child undernutrition: global and regional exposures and health consequences. Lancet. 2008; 371: 243-260.

15. Edmond KM, Zandoh C, Quigley MA, Amenga- Etego S, Owusu-Agyei S, KirkwoodBR. Delayed breastfeeding initiation increases risk of neonatalmortality. Pediatrics 2006; 117: 380-386.

16. Jones G, Steketee RW, Black RE, Bhutta ZA, Morris SS; Bellagio Child Survival Study Group.How many child deaths can we prevent this year? Lancet. 2003; 362: 65-71

17. Giashuddin MS, Kabir M. Duration of breastfeeding in Bangladesh. Indian J Med Res. 2004;119: 267-272.

18. UNICEF. Infant and Young Child Feeding and Care. The state of world's Children. New York. 2007: 43-47.

19. Rao S, Rajpathak V. Breastfeeding and weaning practices in relation to nutritional status of infants. Indian Pediatr, 1992; 29(12): 1533-9.

20. Bushra F, Ahmad N, Hussain T, Manan F. Effect of infant feeding practices on birth interval and morbidity among children in North West frontier province of Pakistan. Journal of Islamic Academy of Sciences. 1995; 8:2, 69-72.

21 Oddy WH, Sly PD, de Klerk NH, et al. Breast feeding and respiratory morbidity in infancy: a birth cohort study. Arch Dis Child.2003; 88; 224228.

22. French GJ, PH Dr. Relationship of morbidity to the feeding patterns of Navajo children from birth through twenty-four months. Am J Clinical Nutr. 1967; 20(5):375.

23. Marian PC. Relationship between infant feeding and gastroenteritis. Saudi Med J. 1981; 2 (suppl): $53-55$.

24. Awasthi S, Malik GK, Misra PK. Mortality patterns in breast versus artificially fed term babies in early infancy: a longitudinal study. Indian Pediatr. 1991; 28(3): 243-8.

25. Agarwal RK. Importance of optimal infant and young child feeding (IYCF) in achieving millennium development goals. Indian Pediatrics. 2008; 45(9): 719-721.

26. World Health Organization. Global Strategy for Infant and Young Child Feeding. Geneva. 2003: 1-8.

27. Bangladesh Demographic and Health Survey. National Institute of Population Research and Training (NIPORT). Mitra and Associate, Dhaka and ORC Macro, USA. 2007: 30-34.

28. WHO (World Health Organization): International Code of Marketing Breast milk Substitutes. Geneva, Switzerland, 1981

29. Ruiz-Palacios GM, Calva JJ et al. Protection of breast-feed infants against compylobacter diarrhea by antibodies in human milk. J Pediatr. 1990; 116(5):707-13

30. Clemens JD, Stanton B, Stoll B, Shahid NS, Banu $H$, Chowdury AKMA. Breast feeding as determinant of severity in shigellosis: evidence for protection throughout the first three years of life in Bangladeshi children. Am J Epidemiol. 1986; 123: 710-20.

31. Feachem RG, Koblinsky MA. Intervention for the control of diarrheal disease among young children: promotion of breast feeding. Bull WHO 1984; 62: 271-91.

32. Briend A, Bari A. Breast feeding improves survival, but not nutritional status, of 12-35 months old children in rural Bangladesh. Eur $J$ clin Nutr. 1989; 43: 603-8.

33. Mitra KA, Rabbani F. The importance of Breastfeeding in minimizing mortality and morbidity from diarrheal diseases: the Bangladesh perspective. J Diarrheal Dis RES 1995 Mar; 13(1):1-7.

34. Chitkara AJ, Gupta S. Infant feeding practices and morbidity. Indian Pediatr. 1987 Oct; 24(10):865-71.

35. NehaKapoor, RajiniThapa. Assessment of Feeding and Mortality Pattern among Children.International Journal of Science and Research (IJSR). Index Copernicus Value (2015): 78.96 / Impact Factor (2015): 6.391 